\title{
Ground Penetrating Radar Survey for the Location and Assessment of the Hydrocarbon Plumes at Gas Station Installations
}

\author{
Jose Vicente Fuente, Rubén Diego, Roberto Fabregad \\ Research \& Develop Department, Geozone Asesores SL, Bétera, Spain \\ Email: j.fuente@gmail.com
}

How to cite this paper: Fuente, J. V., Diego, R., \& Fabregad, R. (2021). Ground Penetrating Radar Survey for the Location and Assessment of the Hydrocarbon Plumes at Gas Station Installations. Journal of Geoscience and Environment Protection, 9, 57-71. https://doi.org/10.4236/gep.2021.912004

Received: October 3, 2021

Accepted: December 14, 2021

Published: December 17, 2021

Copyright (c) 2021 by author(s) and Scientific Research Publishing Inc. This work is licensed under the Creative Commons Attribution International License (CC BY 4.0).

http://creativecommons.org/licenses/by/4.0/

\begin{abstract}
The present paper describes the implementation of GPR 3D survey for detecting and delineating possible remains of hydrocarbon plumes on a gas station. The 3D-imaging was used for the detection of anomalous zones that were analyzed with some relevant signal attributes extracted by digital signal processing. These signal attributes or parameters have been the frequency of the maximum energy concentration on time-frequency distribution and instantaneous amplitude that could be related to the local response of the electromagnetic interaction and the presence of hydrocarbon plumes or soil contaminated areas. The implementation methodology took place at a gas station monitored with a piezometric sensor installation with soil layer information. The 3D-imaging of processed data and its slicing tool permits visualizing expected targets as pipes, tanks and installations in the subsoil exposing the anomalous zones for refined analyses. This further processing has used some spectral attributes of the signal to assess the real presence of the total petroleum hydrocarbons (TPH) providing a new effort to simplify and overcome the current state of the geophysical methods able to assess the presence of hydrocarbon plumes in industrial environments regarding the time cost of the survey and the traceable indication of the spectral shiftment shown in the plume volume.
\end{abstract}

\section{Keywords}

GPR Survey, Time-Frequency Analysis, Instantaneous Amplitude, Slice Tomography, 3D-Reconstruction, Gas Station

\section{Introduction}

The soil contamination by combustible and oil products is referred to when 
undesirable leakage is produced by hydrocarbon spills. These contaminant industrial components are commonly named by Non-Aquose Phase Liquids (NAPL) and it can be distinguished the LNAPL with density lower than the water and the DNAPL that are the higher density than the water components. The subsoil was established as a dynamic system (Che-Alota et al., 2009) when the NAPL has a typical pathway depending on the layers composition and the water distribution. It can be formed by the so-called plumes of contaminants that can be deposited mainly above the fringe region and move along the permeable zone.

The water table depth and the fringe layer immediately above the water table (see Figure 1), where soil has a high concentration of water presence by capillarity, are desirable to be known before starting a remediation process as well as main constitutive layers, sand, clays and the bedrock. All above complex configuration affects the movement and transport of contaminants, especially waterflow on the saturated zone (below water table) and permeability/porosity of the unsaturated zone above the water table (Committee on Source Removal of Contaminants in the Subsurface, 2004).

The dynamic nature of the hydrocarbon contaminant plume is presented in the followed subsoil model based on (Sneddon et al., 2000; Marcak \& Gołębiowski, 2008) that it is relevant to understand the kinetic of the hydrocarbon flow.

When a spill occurs, the DNAPL can move mainly by gravity to the bottom layers crossing the water table and continuing its progression to the aquifer while LNAPL would move depending on the underground water flow and the permeability of the vadose zone. The core of contaminants should be allocated between capillary fringe and phreatic level even though below this level around the aligned leakage point. Also, the seasonal water table changes influence the hydrocarbon formation and deposition. In fact, the more complex

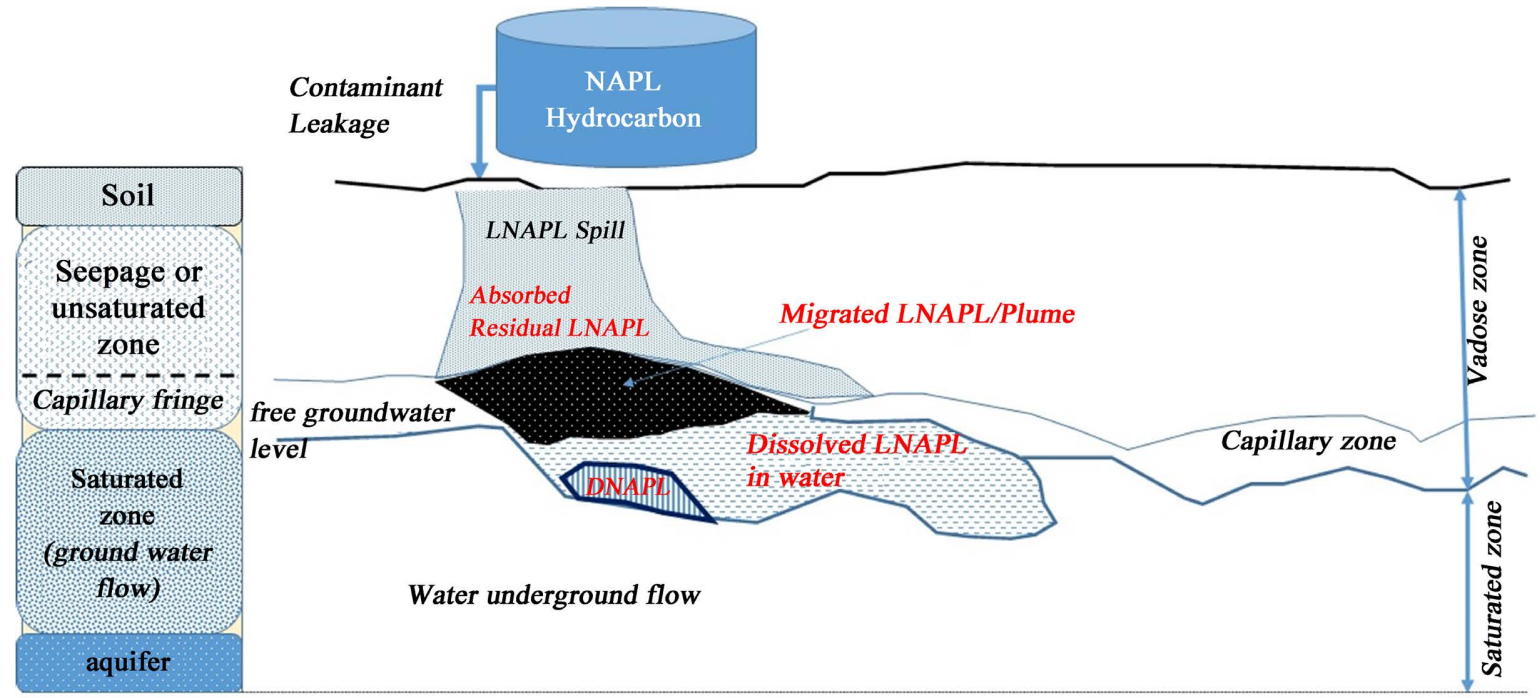

Figure 1. Hydrological model for NAPL diffusion in the contaminated soil. 
and scientific approach for chemical transportation of these phases could be extracted from the doctoral research of J. McCallister (McCallister, 1994) involving the concepts of: 1) Diffusion of molecules from high to low concentration (mainly vapor phases at LNAPL in vadose zone); 2) Advection related with the gas phase particles movement caused by the pressure gradient; 3) Regrouping of colloidal chains by the effect of negative charged particles; 4) Biodegradation process can alter the structure of LNAPL by chemical reaction of some microbial organism; 5) volatilization due to the transfer of gas phase of contaminant of liquid phase (frequently at hydrocarbons mixtures) to the air phase at the vadose zone.

Due to the organic nature of these contaminants, it is very known that the LNAPL presence around the soil changes their electrical conductivity and dielectric properties (Huling \& Weaver, 1991; Sauck, 2000), so that it is a common practice to undertake geophysical on-site investigation based on the measurement of these two properties (Subba-Rao \& Chandrashekhar, 2014; Werkema et al., 2003). Some illustrative research proposed the induced polarization time or chargeability as a good indicator of hydrocarbon presence (Tejero \& López, 2013). Other efforts focused on joint both techniques ERT and GPR to verify the HTP presence (Hamzah et al., 2008).

Most geophysical research has revealed that an increase in hydrocarbon concentration in soil is directly proportional to the increase in electrical resistivity $\varepsilon$ and a decrease in dielectric permittivity $\varepsilon_{\mathrm{r}}$ (Durnford et al, 1997) but relatively recent research indicates that the changes in conductivity/dielectric are more complex than a few intuitive trends on both parameters.

With any aim to be exhaustive, several authors have reported the increasing of the electrical resistivity and decreasing the dielectric of a plume (De Ryck et al., 1993) however other researchers found opposite trend (Benson et al., 1997). In some survey sites, at the vadose zone can be detected regions of low apparent resistivities coincident with attenuated GPR reflections or shadow zones although the predominant response of LNAPL concentrations would be the high apparent resistivities or low conductivities with bright GPR reflections below the water table. In some cases, a GPR reflection layer parallel to water table would delimitate the fringe zone. Sauck et al. (Sauck et al., 1998) try to put light on this controversial behavior and established a dynamic soil model that explains the high values of conductivity for LNAPL contaminant associated with the dissolved parts in the groundwater related with the aerobic biogenic degradation of the hydrocarbons. Also, it was observed high resistivities were measured when contaminant spills were recent and fresh contaminant has not reacted with the host media. Biodegradation processes introduce changes in the conductivity/dielectric signatures measured on the affected area. Che-Alota et al. (Che-Alota et al., 2009) describes a conceptual model for bulk electrical conductivity of the hydrocarbon mass and its changes by biodegradation and mitigation process. Complementary for the dielectric response, when the biodegradation process has been started the GPR signal attenuation (shadow zones) also can be associated with the increase in 
electrical conductivity due to biodegradation of hydrocarbons in soil (Srigutomo et al., 2016).

In other words, the light hydrocarbon free product and associated dissolved plumes are dynamic systems, with their character changing or evolving in time and position within the plume. Therefore, strong recommendations and efforts are suggested to researchers to consider long-time monitoring using the geophysical techniques and also building some representative set-up of small scale-experiment with LNAPL contaminated scenarios in order to gain an improved understanding of the behavior of the electrical and dielectric signal responses around different soil compositions (Castillo, 2013; Bertolla et al., 2004). Doing so, removing hydrocarbon contaminant-mass by natural or forced process can be monitored producing tomographies or sections by temporal geophysical surveys.

The final objective of this research is to stablish a testing procedure for oil station based on geophysical testing and time-frequency analysis of ground penetration radar exploiting the interaction mechanisms of relaxation between LNAPL and electromagnetic wave described in some works of the literature review.

Similar research has been developed to detect PAHs (Polycyclic Aromatic Hydrocarbons) exploiting the information contains in the frequency dependent time attributes when the success is clearly reported for the cases of important contrast the conductivity and dielectric values of the surrounding area (Chen et al., 2012). Other research constitutes precedents in the use of spectral attributes as the power spectra from simulated or synthetic traces to detect the presence of LNAPL even though when dielectric constant does not permit the detection and the use of the instantaneous amplitude or phase was described to get more sensitive to the LNAPL detection (Orlando, 2002) however 3D-survey was not used to clearly delimitation of more suitable zones to contain the plume. In this sense, the present work shows how the spectral shifment corresponding to the anomalous zones located by GPR-3D and its slicing analysis reveals an innovative tool to determine the presence of hydrocarbon in the complex subsoil affected by natural migration direction and clear watertable level.

In this paper, the research addressed to find evidence of the spectral response changes and some complex signal attributes of the GPR traces that contain soil contaminants from the hydrocarbon leakages. The most suitable soil volume affected by plume has been delimited by GPR-3D. The paper was structured in different sections, starting with the methodology description and the gas station information about existing facilities and piezometric installation for control and monitoring the eventual contamination.

\section{Planning and Methodology}

\subsection{Site Information and Planning}

The gas station extends an area of $1800 \mathrm{~m}^{2}$ dedicated for production and service 
activities as offices, shop and hydrocarbon separator, refueling and some other parts as parking and access roads. The station has six steel combustible tanks of simple wall with vent probes for leakage detection. The total capacity of each tank is 30.000 liters and 1 out 6 was not used. Tanks 1, 2 and 3 are located 3.5 meters in depth orientated to the north and tanks 4,5 and 6 are located at 4.5 meters in depth and orientated to the south from the area of refueling jets.

The refueling zone extends under the metallic roof covering an area of 196.1 $\mathrm{m}^{2}$ just in the exit of the shop with two main jet machines. In this area since six vent pipelines cross from the north to the south supplying the jets located at 0.5 meters in depth. Other secondary pipelines connect both jet machines around $0.3 \mathrm{~m}$. in depth. Some other services were pluvial, water suppliers and telecommunication mainly in perpendicular direction from the road to the shop and some perimeter services as lighting where shallow in the first half meter. Two main installations for the combustible separation and storage were at the left side (North) and right side (South) distanced about 30 meters from the centered point (manhole between jets, see Figure 2).

It was installed six piezometers to control and monitor the soil contamination and periodically is carried out the soil samples characterization and the recuperated water below the water table level. The P-1 and P-2 located at 24.5 and 38.4 meters at left and right from the referenced manhole were firstly installed. However, the main underground water flow is found from north to south (left toright in Figure 2). The P-1 controls the area of the tanks 1, 2 and 3 (at the South) and in-coming underground water and the P-2 controls eventual spills from tanks 4, 5 and 6 (at the North) and the out-coming underground water providing some information from vadose zone and from saturated zone.

The P-3 (30.4 meters), P-4 (23.7 meters), P-5 (13 meters) were located

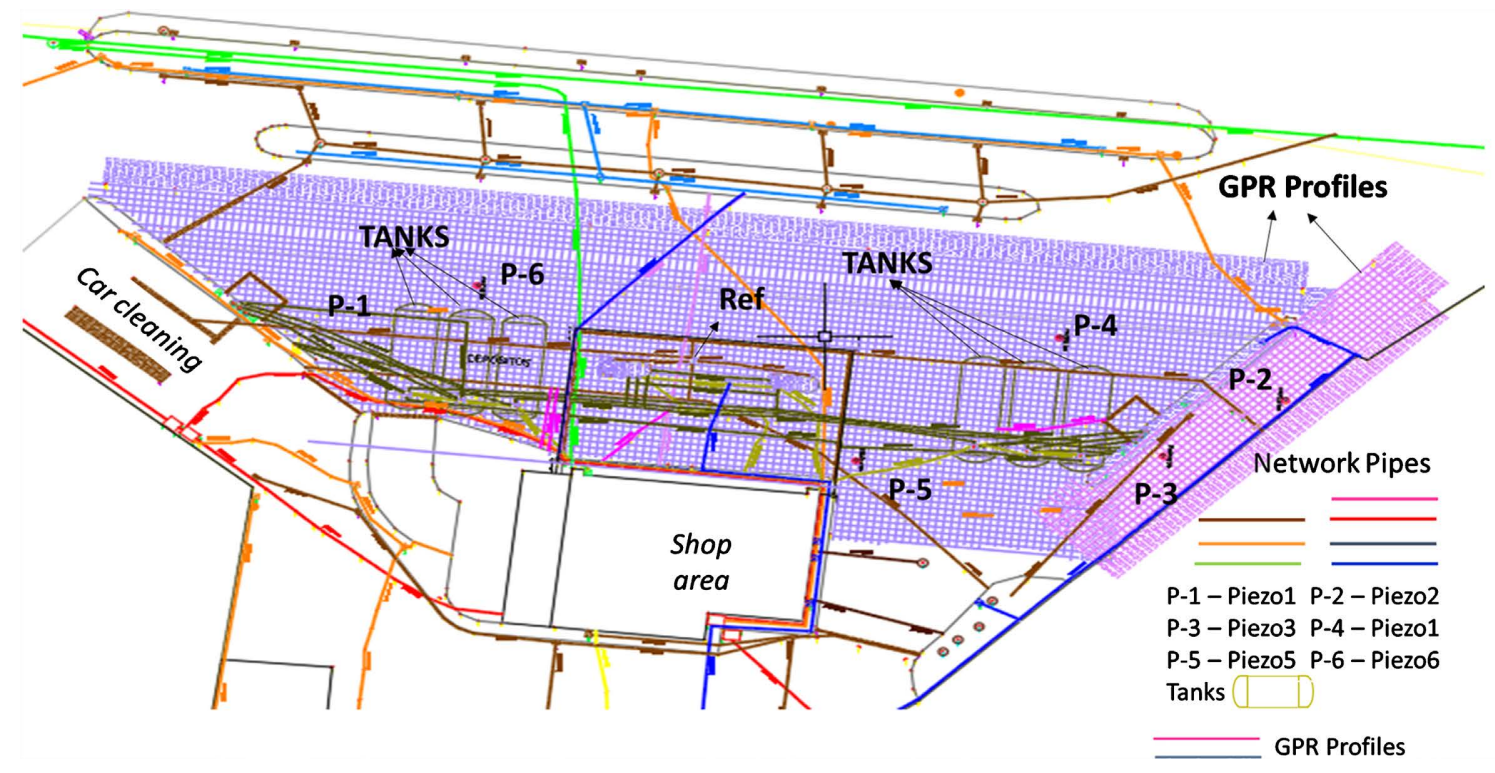

Figure 2. Supplier services, pipelines, piezometers (P-X) and GPR profiles implementation at the gas station cartography. 
around the area of tanks 4, 5, and 6, while the P-6 (15 meters) were installed in front to tanks 1, 2 and 3 addressed to the West. It was found some water presence at the next depth range between the 3.1 meters for P-1 until the 3.60 and 3.73 meters of the P-2 and P-3 respectively. It is assigned to a fringe zone due to the permeable layer of anthropic fillers at this depth. Free water flow can be found since from the next layer of vegetal terrain and organic compounds (see Figure 3).

Figure 2 shows a cartographic representation or map of service network at the gas station and perimetral pipes and installations. This kind of service can be done using radio-detection and GPR combination techniques (Prego et al., 2017). The services can be rapidly provided by in-situ soil painting or processing the information for 2D-map representation.

The next figure shows the soil composition in depth according to the drill hole for piezometric sensor installation.

The main significant change in depth layers was found between P-5 and P-4. The fringe and water table level were set according to the layer composition and moisture found at soil sample recuperated. The soil investigation was assessed according to the criteria of the standard proposed at the RD9/2005 (2005). The reference ground level (NGR) establishes a limit to the TPH concentration of 50 $\mathrm{mg} / \mathrm{kg}$ for unacceptable risk and the limit of $100 \mathrm{mg} / \mathrm{kg}$ where the authorities can declare contaminated soil and propose mitigation procedures for this soil. The soil samples were analyzed to determine the heavy or dense TPHs and also Benzene, Toluene, Ethylbenzene and Xilenes (BTEX). On the other hand, RD1514/2009 (2009) establishes the underground water protection against the contaminants and deterioration.

The soil contamination was analyzed in two phases. One exploratory phase, regarding the installed P-1 and P-2. At 0.6 meter in depth, an elevated TPH and BTEX concentration over the limit was found. The detailed analysis phase does

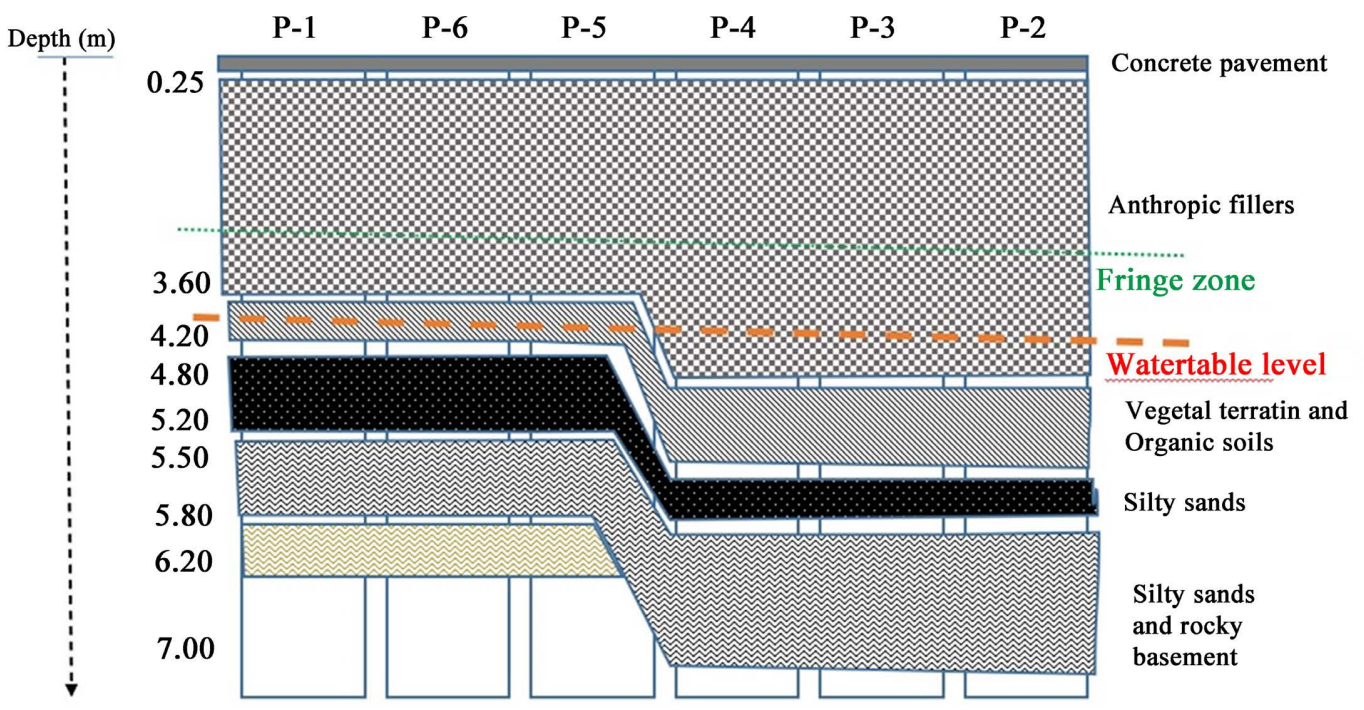

Figure 3. Stratigraphic composition at the piezometric boreholes. 
not find any limit exceeded even it was observed some presence of concentration levels of BTEX at P-1 below the limits so that it was considered that the only source of contaminant presence in the area came from the vent pipeline drilling of the gasoil tank placed at left side. Nevertheless, in order to clarify the situation a GPR survey to recover some non-intrusive information from the total area has been proposed.

\subsection{Used Equipment}

The pipeline network location has been conducted using radiodetection techniques (RD4000RX from $\mathrm{SPX}^{\odot}$ ) and depth verification with GPR equipment $\left(\right.$ IDS Himod ${ }^{\odot}$ ). The detection and delineating possible plume contaminants were carried out with GPR equipment by using RIS MF processor and dual frequency antenna $200-600 \mathrm{MHz}$ with a total area of $38 \times 43 \mathrm{~cm}$.

In Table 1 is shown the main parameters of the exploration that are calculated according to the conventional formulas that relates resolutions $\Delta_{v}$ and $\varepsilon_{\text {hor }}$, signal achieved depth $z$ and the wavelength $\lambda$ (Rial et al., 2007). It is well known that the vertical and lateral resolutions of the antenna are related with the wavelength $\lambda$ in the materials. Therefore, assuming a dielectric constant of $\varepsilon_{\mathrm{r}} \sim 8$ as an averaged value for that subsoil, both resolutions are the minimum distance for two points to be separately observed or discriminated giving the vertical resolution by $\Delta_{V}$ and the horizontal resolution $\varepsilon_{\text {hor }}$, as the radius of the shadow cone radiation at a fixed depth $z$.

\subsection{Implementation Procedure}

The dual frequency antenna permits to collect two datasets centered on the correspondent working frequency at the same time. Doing so, it saves much time of survey. It was implemented to grids with perpendiculars straight profiles separated 0.5 meters between adjacent profiles. The grid 1 (purple color at Figure 2) consists of 55 profiles aligned south to the north and the correspondent perpendicular 170 profiles from West (W) to East (E). The grid 2 (magenta color) comprises 61 profiles with Northeast (NE) to Southwest (SW) and the correspondent 9 perpendicular profiles NW-SE (see Figure 2).

\subsection{Signal Processing and Representation.}

It was used the GPR-Slice ${ }^{\odot}$ software to process the data set combining the grids

Table 1. Vertical and lateral resolution of used antenna for a giving depth $\mathrm{z} \& \varepsilon_{\mathrm{r}}$.

\begin{tabular}{ccc}
\hline Propagation Parameters (accuracy and depths) & $200 \mathbf{M H z}$ & $600 \mathbf{M H z}$ \\
\hline$\Delta_{v}(\mathrm{~mm})$ & 130 & 44 \\
$\varepsilon_{\text {hor }}(\mathrm{mm})-\mathrm{z} \sim 1 \mathrm{~m}$. & 930 & 760 \\
Time propagation (ns) & 180 & 80 \\
Achieved Depth (m) & 7.5 & 3 \\
\hline
\end{tabular}


but separately by working frequencies. The processing flow consists of the following steps: 1) Zero-time correction; 2) Background removal; 3) Wave velocity estimation (by fitting hyperbolic curve in a known diameter pipeline cross reflection); 4) Bandpass filter + manual gain in depth; 5) Kirchhoff migration; 6) Hilbert transform.

The slicing process consists of the data interpolation of processed signal traces and creating a $3 \mathrm{D}$-volumen to assign the interpolated data in the volume when ground is reference depth after removing the background echo in the filter stage (a). The total scanned area covers 5.379 linear meters, and the accuracy is set to $7.5 \mathrm{~cm}$. The interpolation depth is $75 \mathrm{~cm}$ covering 1.5 time the cell length and the interpolation method selected is the krigging that is indicated for geophysical purposes. The slices were created using an overlapping $50 \%$ and $9 \mathrm{~cm}$ of thickness to integrate values. These parameters return a total amount of 87 slices for $200 \mathrm{MHz}$ and 40 slices for $600 \mathrm{MHz}$. This procedure was used to produce 2D and $3 \mathrm{D}$ representation to detect and locate the anomalous zone.

Some other signal attributes related with the spectral domain as follows:

1) maximum frequency on the time-frequency (MFQ) transform of some individual traces. To obtain the time-frequency representation uses the S-transform based on continuous wave transform CWT $(t, d)$ of a giving function $h(t)$, where $\mathrm{d}$ is a dilation time that control resolution between time and spectra.

$$
C W T(\tau, d)=\int_{-\infty}^{\infty} h(t) \cdot w(t-\tau, d) d t
$$

where the $w(t, \tau)$ is the fundamental decomposition of mother wavelet The S-transform is time and frequency domain is defined by the multiplied phase factor as it can be found at (Stockwell et al., 1996)

$$
S(t, f)=e^{i 2 \pi f \tau} \cdot W(\tau, d)
$$

2) the instantaneous amplitude (IAM) is calculated from the analytic signal, and it is related with the reflectivity strength, reducing the random appearance of the signal in the radargram that it is very convenient on data with several reflections.

The procedure focuses in analyzing the expected changes in the spectral response of the signal traces propagated in some area affected by the presence of LNAPL in vadose zone or possible DNAPL in saturated zone.

\section{Results}

This section may be divided by subheadings. It should provide a concise and precise description of the experimental results, their interpretation as well as the experimental conclusions that can be drawn.

\subsection{Results from the $600 \mathrm{MHz}$ Frequency Survey}

The high frequency at the dual antenna is used for the detection of network pipes as supply and sanitation, telecommunications, lighting and vent conductions. The GPR processed data jointly with the geographic information provides 
the $2 \mathrm{D}$-slices at different depths. The shorter wavelength $\lambda_{600 \mathrm{M}}$ is about the $20 \mathrm{~cm}$ is able to recuperate the shape of the buried pipes with more accuracy than the larger wavelength with an associated $\lambda_{200 \mathrm{M}}$ of $48 \mathrm{~cm}$. The installations and the contrast of different pavements are also better observed. The right side of tanks $(1,2 \& 3)$ were perfectly sized as $6 \times 2 \times 2.5 \mathrm{~m}^{3}$ ranged between 1 and 3.5 meters in depth while the left side of tanks $(4,5 \& 6)$ were rarely sized between 2 and 4.5 meters in depth. As it goes deeper, the subsoil reflections seem to delineate specific shapes and leaves the random appearance or noise effect. Although, the phreatic is reported between $\mathrm{z} \sim 3.1-3.7$ meters in depth, the $2 \mathrm{D}$-slices with 600 $\mathrm{MHz}$ has not been detected as a contact layer but it is showed at processed radargrams.

Considering the phreatic level around the 3.6 - 4.3 meters of depth, this frequency permits the observation of the vadose zone.

The red or hot colors mean the presence of signal returned by reflection and diffraction while blue or cool colors indicate no reflection on that part by absence of dense materials or presence of homogenous materials with low dielectric contrast. Regarding the 3D-representation in Figure 4, it was detected some anomalous zones (A1, A2 and A3) in depth regarding some slices around the phreatic level associated to reflexive zones as can be observed at the next Figure 5.

Scrolling the slice representation up and down the area and delineation of this

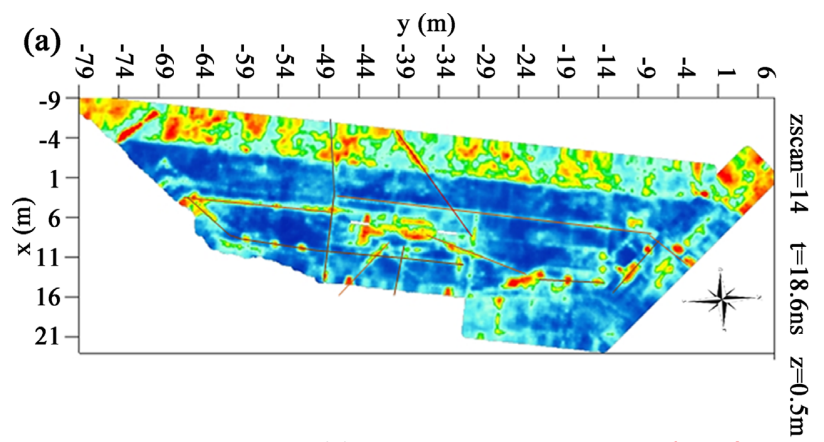

(b) $y(\mathrm{~m})$

(c)
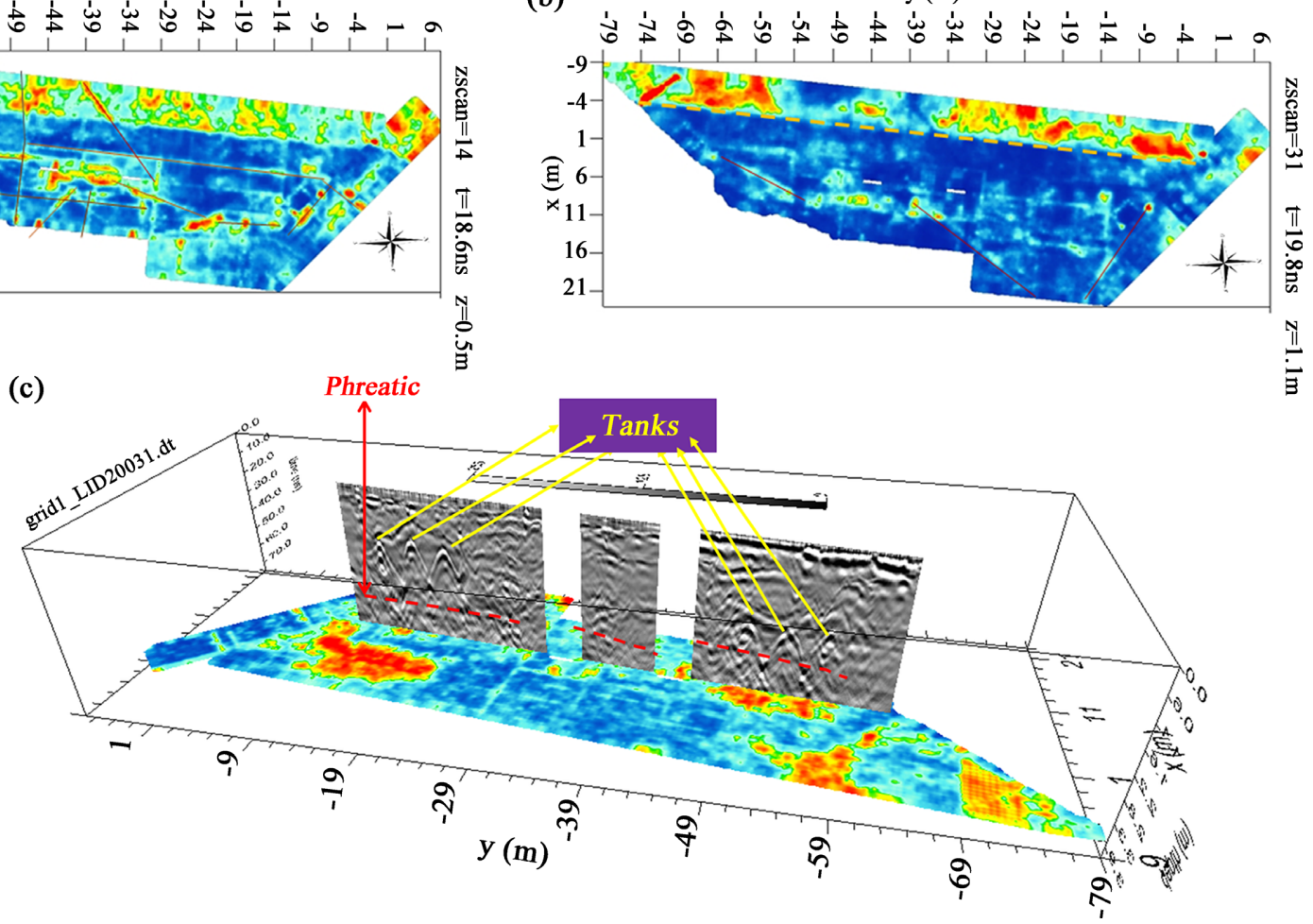

Figure 4. Slices at (a) $\mathrm{z} \sim 0.5 \mathrm{~m}$; (b) $\mathrm{z} \sim 1.1 \mathrm{~m}$; (c) combined 2D-representation using $600 \mathrm{MHz}$ at the shallow zones enhanced road and pipeline networks. 
suspected zones are delimited. It was selected a depth cut or slice at $\mathrm{z} \sim 2.9 \mathrm{~m}$. when the three anomalous reflective zones are shown. Also, it was found the general descendent slope in some layers especially in the A2 and A3 zones. So, the layers move down at the east and slightly to north (bottom and right direction on the slice respectively). Other kind of representation can be used to classify the possible nature of the reflections from the anomalous zone.

\subsection{Results from the $200 \mathrm{MHz}$ Frequency Survey}

The Figure 6 shows that the radargrams and consequently the slices extend until 8 meter in depth for $200 \mathrm{MHz}$ but the signal is attenuated since from $\mathrm{z} \sim 5.5$ meters. Yellow indications remark the abrupt descendent contact layer can be seen at A1 and A2 zones while the A3 has descendent contact that turns into flat and horizontal contact at the right location of the tanks $4,5 \& 6$ (marked in purple) showing a reflective zone at this area around the 3 meters in depth.

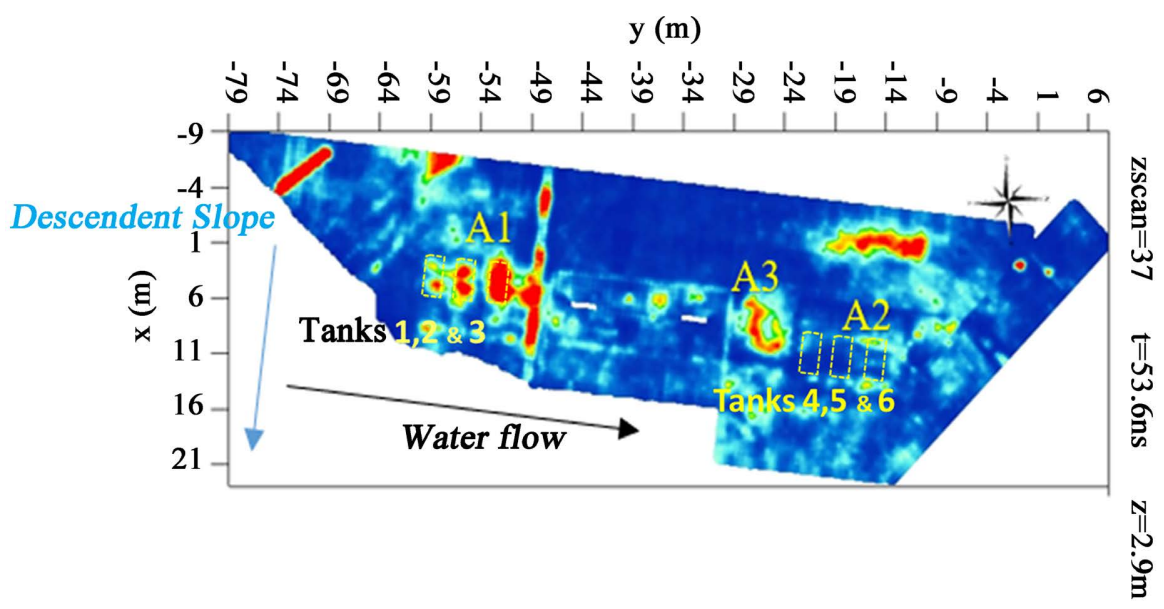

Figure 5. Slice at $\mathrm{z} \sim 2.9 \mathrm{~m}$. using $600 \mathrm{MHz}$ with presence of left tanks numbered 1, 2 and 3 and the perimetral wall of excavation for tanks numbered 4, 5 and 6 .

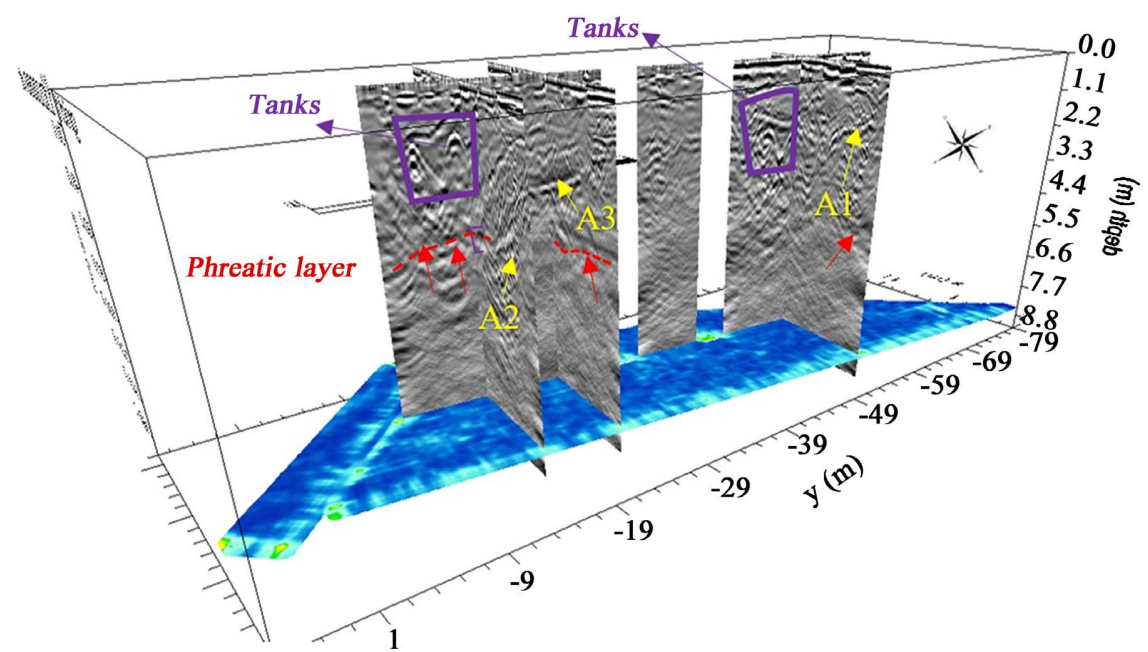

Figure 6. 3D-representation slice and migrated radargramas for $200 \mathrm{MHz}$ with indications of the identified structures and geological objects. 
While $\mathrm{A} 1$ and $\mathrm{A} 2$ show their reflective zones composed by multiple and small reflections, the A3 show clear and linear contacts and uniformed reflection so that it seems that their nature could be different.

\subsection{Evaluation of Anomalous Zone by the Instantaneous Amplitude (IAM) and Time-Frequency Analysis (MFQ)}

From the above representation combing slices and processed radargrams it can be selected from the anomalous zones (reflexive or shadow zones) some GPR traces to extract the spectral attributes. The large and transversal profiles (from North to South) were the so-called grid1-LID20012 and, grid1-LID20019. The three shorter and longitudinal profiles were aligned from West to East called by grid1-LID20085, grid1-LID20105 and grid1-LID20176. Each profiles crosses specific interesting zones.

The grid1-LID20012 crosses P-4 $(12 \mathrm{~m}$.) and the A2 zone, the western and shallow part of A3 and the cross the P-6 (45 m.) and the combustible storage installation at $65 \mathrm{~m}$. The grid1-LID20019 is parallel to the grid-LID20019 crossing the $\mathrm{A} 2$ zone $(6-12 \mathrm{~mm}$ ) and the tanks numbered 4,5 and 6 , the A3 zone (18 - 22 $\mathrm{m}$.) and the $\mathrm{A} 1$ zone and tanks 1,2 and 3 (at $46 \mathrm{~m}$.) The longitudinal profiles correspond to a A2 (ended 85), A3 (ended 105) and A1 (ended 176).

Next Figure 7 shows the representation for Instantaneous Amplitude Radargram (a) and the TFD (S-transform) at the length $46 \mathrm{~m}$. for the grid1-LID20019 transversal profile. The IAM signal attributes permit the area delimitation of the possible hydrocarbon plume, the MFQ attribute calculated from the spectral shift of the working frequency is the key parameter to discriminate hydrocarbon presence or not. Also, the phreatic level is better detected with standard processed radargrams. In the longitudinal profiles, the phreatic level and fringe associated layer has been detected as a low frequency below the descendent slope contacts reported at all anomalous zones in the western part of all areas of the gas station.

The spectral shipment $\Delta \mathrm{f}$ of the MFQ from the referenced central frequency of $200 \mathrm{MHz}(0.2 \mathrm{GHz})$ has been measured for the zones of interest and located in the $2 \mathrm{D}$ view plant (Figure $7(\mathrm{c})$ ). It is noticed that the effect of the reflections on the industrial installation causes some frequency shift but is randomly depending on the obliquity of the exposed area, depth and shape of them. Therefore, it should be analyzed each by one profile to see if there is a trend on this frequency shift or not. The reflectivity area below the descendent contact layer presented at A2 does not cause spectral shift of the maximum energy reflected negative shiftments.

According to the red color for the $\Delta \mathrm{f}$ of the MFQ indicates high spectral shift (positive values) reported that are compatible with hydrocarbon presence especially from the reflective areas. So that, the reflective layers below the descendent slope contact of A2 zone have no evidence of the hydrocarbon presence. In fact, it is compatible with some mixed silt and rock layers in the western part of A2 zone regarding the pits. The specific zone between low depth of the 
(a)

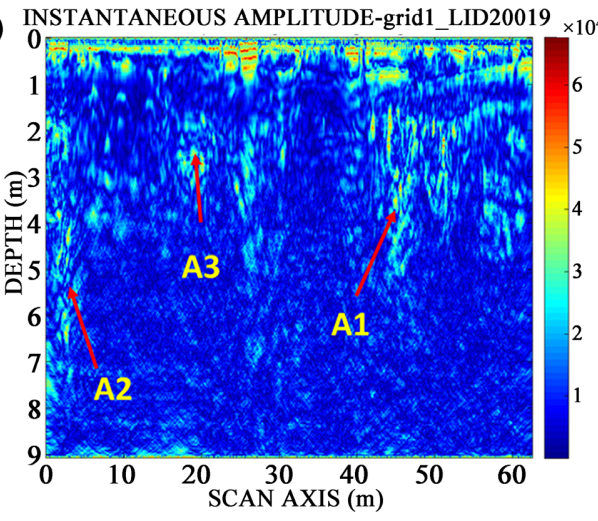

(b)

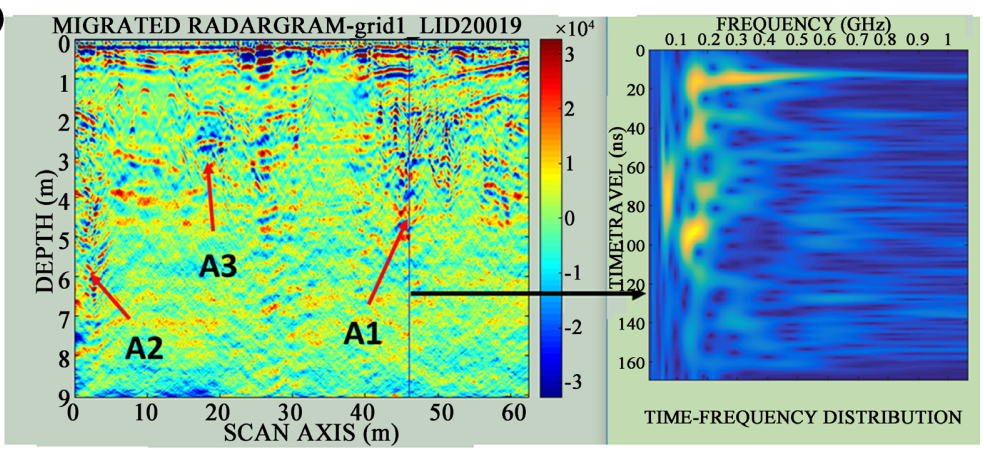

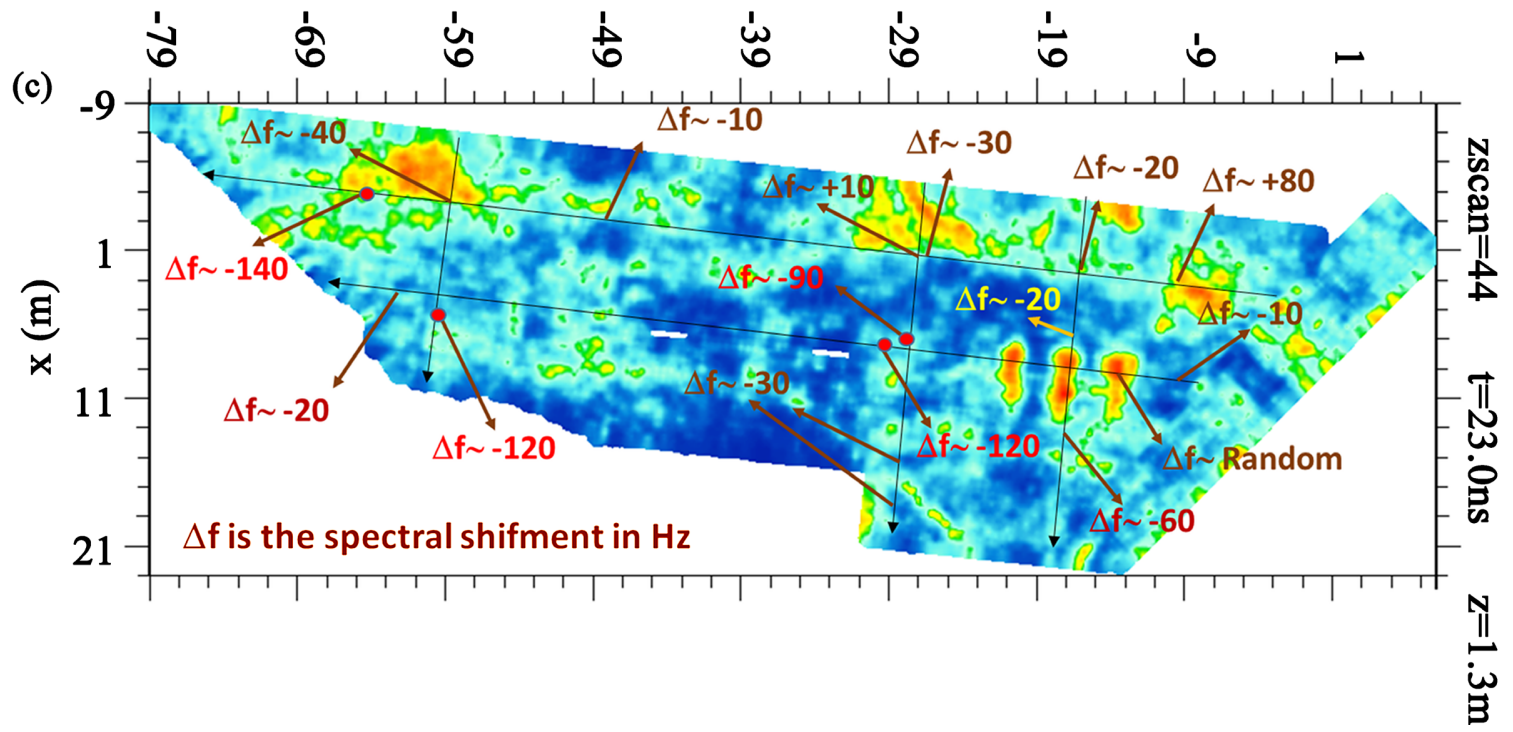

Figure 7. Instantaneous Amplitude radargram, IAM (a), migrated radargram and TFD with MFQ of the trace grid1-LID20019 (b) and the located $\triangle \mathrm{f}$ of the MFQ at (c).

descendent contact layer and phreatic layer in the $\mathrm{A} 3$, the spectral attributes are compatible of the NAPL presence. The spectral shift values in the Al reveal an area of $12 \mathrm{~m}^{2}$ with some hydrocarbon signatures at the range $3-4.5$ meters in depth aligned with interchange combustible installations.

This main achievement coming from processing data of GPR survey is partially consistent with the piezo readings when P-1 registers some exceed acceptable limits of the Xilenes concentration $(720>440) \mu \mathrm{g} / \mathrm{l}$. This non-desirable spill was caused by occasional breakage of vent pipes that were rapidly repaired.

\section{Conclusion}

The implementation of the on-site procedure based on the GPR survey and subsequently signal processing recorded has been revealed as a promising tool for locating and delineating the hydrocarbon plumes according to the founded response of the proposed spectral attributes as the IAM and the MFQ and its parameter of spectral shift $\Delta \mathrm{f}$ from the central frequency of the used antenna.

Although the best approach is to apply different techniques and contrast with 
chemical and analytical tests, this work constitutes an example of a single geophysical method as it is the GPR that requires the analysis of the various signal parameters and representations for the effective location of hydrocarbon plumes when migration flow is produced.

The lay-out of grid profiles permits recover of the interpolated representation of processed data using slices and radargrams (2D) and combined sections (3D). The reflective and shadow zone would be considered as suspected zones. The GPR profiles crossing the abovementioned zones would be analyzed by spectral domain variables to distingue which are compatible with hydrocarbon presence or not, while IAM radargram computes from migrated radargram are used to size the areas in $2 \mathrm{D}$-sections.

In the studied facility, some HTP remains have been detected in the suspected zones of its subsoil near to the tanks numbered 1, 2, 3 and the interchangeable installation (A1) shown in Figure 2 and Figure 5 where tanks are conveniently located and denoted. Eventually, other HTP remains could be detected over the water table level at the $\mathrm{A} 3$ zone. The area and values coming from $\mathrm{A} 3$ were smaller than obtained in the A1 so that it aims to an event of HTP migration following the underground waterflow dynamic system that seems to be consistent with the piezo installation readers dedicated to monitoring possible HTP leakage presence and movements.

\section{Acknowledgements}

This research was funded by Programa Torres-Quevedo of the Spanish Ministerio de Ciencia e Innovación, grant number PTQ-17-09251.

The authors express thanks to Xesmega by the collaboration and management in this application and interpretation on the contamination readings.

\section{Conflicts of Interest}

The authors declare no conflicts of interest regarding the publication of this paper.

\section{References}

Benson, A. K., Payne, K. L., \& Stubben, M. A. (1997). Mapping Groundwater Contamination Using DC Resistivity and VLF Geophysical Methods-A Case Study. Geophysics, 62, 80-86. https://doi.org/10.1190/1.1444148

Bertolla, L., Porsani, J. L., Soldovieri, F., \& Catapano, I. (2004). GPR-4D Monitoring a Controlled LNAPL Spill in a Masonry Tank at USP, Brazil. Journal of Applied Geophysics, 103, 237-244. https://doi.org/10.1016/j.jappgeo.2014.02.006

Castillo, M. P. (2013). Using Ground-Penetrating Radar in the Investigation of LNAPL Contamination within a Controlled Environment. Master's Thesis of Science in Environmental and Geomatic Engineering, Polo Territoriale Di Como.

Che-Alota, V., Atekwana, E. A., Sauck, W. A., \& Werkema, D. D. (2009). Temporal Geophysical Signatures from Contaminant-Mass Remediation. Geophysics, 4, B113-B123. https://doi.org/10.1190/1.3139769 
Committee on Source Removal of Contaminants in the Subsurface (2004). Contaminants in the Subsurface: Source Zone Assessment and Remediation (pp. 24-29). National Research Council.

De Ryck, S. M., Redman, J. D., \& Annan, A. P. (1993). Geophysical Monitoring of a Controlled Kerosene Spill. In Proceedings of the Symposium on the Application of Geophysics to Engineering and Environmental Problems (SAGEEP'93) (pp. 5-20). European Association of Geoscientists \& Engineers.

https://doi.org/10.3997/2214-4609-pdb.209.1993_003

Durnford, D., McWhorter, D. B., Miller, C. D., Swanson, A., Marinelli, F., \& Heather, T. (1997, October). DNAPL and LNAPL Distributions in Soils. Experimental and Modelling Studies.

https://www.researchgate.net/publication/235103269_DNAPL_and_LNAPL_Distributi ons_in_Soils_Experimental_and_Modeling_Studies

Hamzah, U. M. A., Ismail, M. A., \& Samsudin, A. R. (2008). Geophysical Techniques in the Study of Hydrocarbon-Contaminated Soil. Bulletin of the Geological Society of Malaysia, 54, 133-138. https://doi.org/10.7186/bgsm54200820

Chen, H.-W., Fan, C.-C., Chen, S.-Y., \& Lu, C.-M. (2012). Detection and Analysis of LNAPL Contaminated Site by Integrated Time-Lapse GPR Surveys. In 2012 14th International Conference on Ground Penetrating Radar (GPR) (pp. 764-768). Institute of Electrical and Electronics Engineers.

https://doi.org/10.1109/ICGPR.2012.6254964

Huling, S. G., \& Weaver, J. W. (1991). Dense Non-Aqueous Phase Liquids, Ground Water Issue. Environmental Research Laboratory, United States Environmental Protection Agency (EPA).

Marcak, H., \& Gołębiowski, T. (2008). Changes of GPR Spectra Due to the Presence of Hydrocarbon Contamination in the Ground. Acta Geophysica, 56, Article No. 485. https://doi.org/10.2478/s11600-008-0003-4

McCallister, J. T. (1994). Experiment to Test Ground Penetrating Radar for Gasoline Detection. Bachelor Thesis of Science in Geology and Mineralogy, Ohio State University.

Orlando, L. (2002). Detection and Analysis of LNAPL Using the Instantaneous Amplitude and Frequency of Ground-Penetrating Radar Data. Geophysical Prospecting, 50, 27-41. https://doi.org/10.1046/j.1365-2478.2002.00288.x

Prego, F. J., Solla, M., Puente, I., \& Arias, P. (2017). Efficient GPR Data Acquisition to Detect Underground Pipes. NDT\&E International, 91, 22-31.

https://doi.org/10.1016/j.ndteint.2017.06.002

RD1514/2009 (2009). Regulación de la protección de las aguas subterráneas contra la contaminación y el deterioro (BOE Num 225). Boletin Oficial del Estado.

RD9/2005 (2005). Relación de actividades potencialmente contaminantes del suelo y los criterios para la declaración de suelos contaminados, Ministerio de la Presidencia (BOE num. 15, pag. 1833). Boletin Oficial del Estado.

Rial, F. I., Pereira, M., Lorenzo, H., Arias, P., \& Novo, A. (2007). Vertical and Horizontal Resolution of GPR Bow-Tie Antennas. In 2007 4th International Workshop on, Advanced Ground Penetrating Radar (pp. 187-191). Institute of Electrical and Electronics Engineers. https://doi.org/10.1109/AGPR.2007.386549

Sauck, W. A. (2000). A Model for the Resistivity Structure of LNAPL Plumes and Their Environs in Sandy Sediments. Journal of Applied Geophysics, 44, 151-165. https://doi.org/10.1016/S0926-9851(99)00021-X

Sauck, W. A., Atekwana, E. A, \& Nash, M. S. (1998). Elevated Conductivities Associated with an LNAPL Plume Imaged by Integrated Geophysical Techniques. Journal of En- 
vironmental and Engineering Geophysics, 2, 203-212.

Sneddon, K. W., Olhoeft, G. R., \& Powers, M. H. (2000). Determining and Mapping DNAPL Saturation Values from Non-Invasive GPR Measurements. In Proceedings of Symposium on the Application of Geophysics to Engineering and Environmental Problems (SAGEEP 2000) (pp. 293-302). Environmental and Engineering Geophysical Society. https://doi.org/10.4133/1.2922755

Srigutomo, W., Trimadona, \& Agustine, E. (2016). Investigation of Underground Hydrocarbon Leakage Using Ground Penetrating Radar. Journal of Physics IOP Conference Series, 739, Article ID: 012137. https://doi.org/10.1088/1742-6596/739/1/012137

Stockwell, R. G., Mansinha, L., \& Lowe, R. P. (1996). Localization of the Complex Spectrum: The S-Transform. IEEE Transactions on Signal Processing, 44, 998-1001. https://doi.org/10.1109/78.492555

Subba-Rao, Ch., \& Chandrashekhar, V. (2014). Detecting Oil Contamination by Ground Penetrating Radar around an Oil Storage Facility in Dhanbad, Jharkhand, India (2014). Journal of Indian Geophysical Union, 18, 448-454.

Tejero, A., \& López, A. E. (2013). El método de polarización inducida aplicado en la contaminación de suelos por hidrocarburos. Boletín de Sociedad Geológica Mexicana, 65, 1-8. https://doi.org/10.18268/BSGM2013v65n1a1

Werkema, D. D., Atekwana, E. A., Endres, A. L., Sauck, W. A., \& Cassidy, D. P. (2003). Investigating the Geoelectrical Response of Hydrocarbon Contamination Undergoing Biodegradation. Geophysical Research Letters, 30, 1647-1653.

https://doi.org/10.1029/2003GL017346 